Check for updates

Cite this: RSC Adv., 2019, 9, 26825

Received 20th June 2019

Accepted 17th August 2019

DOI: $10.1039 / c 9 r a 04636 d$

rsc.li/rsc-advances

\section{Low temperature synthesis and characterization of single phase multi-component fluorite oxide nanoparticle sols $\dagger$}

\author{
Mariappan Anandkumar, (D) Saswata Bhattacharya and Atul Suresh Deshpande (D) * \\ We report for the first time a simple, scalable approach for the synthesis of single-phase multi-component \\ fluorite oxide nanoparticle sols: $\mathrm{Gd}_{0.2} \mathrm{La}_{0.2} \mathrm{Y}_{0.2} \mathrm{Hf}_{0.2} \mathrm{Zr}_{0.2} \mathrm{O}_{2}$ (GLYHZ) and $\mathrm{Gd}_{0.2} \mathrm{La}_{0.2} \mathrm{Ce}_{0.2} \mathrm{Hf}_{0.2} \mathrm{Zr}_{0.2} \mathrm{O}_{2}$ \\ (GLCHZ) using chemical co-precipitation followed by peptization in acidic medium under mild \\ conditions $\left(\leq 80^{\circ} \mathrm{C}\right.$ ). High resolution transmission electron microscopy (HRTEM) along with selected \\ area electron diffraction (SAED) studies confirm fully crystalline single-phase cubic fluorite nanoparticles \\ having a particle size of about 2-3 nm with a narrow size distribution was obtained. The powder X-ray \\ diffraction (XRD) and Rietveld refinement studies of samples calcined at $500{ }^{\circ} \mathrm{C}$ for 4 hours confirm \\ a single phase solid solution and a lack of secondary phases.
}

\section{Introduction}

The pursuit of novel materials is driven by a persistent need for enhancement in the structural and functional properties of materials used for advanced applications. In this regard, new classes of complex multicomponent materials with high configurational entropy, such as oxides, nitrides, and carbides, have been reported. ${ }^{1-19}$ In particular, the properties of highentropy oxide systems seem quite promising. However, the reported synthesis methods employed to obtain a single phase material are tedious and energy intensive. Different synthesis methods, such as ball milling, ${ }^{17,19,20}$ nebulized spray pyrolysis, ${ }^{11,13}$ co-precipitation, ${ }^{16}$ reverse-co-precipitation, ${ }^{12}$ and hydrothermal method, ${ }^{16}$ were followed to obtain high-entropy oxides. These processes typically involve a high temperature heat treatment step to obtain a single phase solid solution. ${ }^{15,19,20}$ Chen et al. ${ }^{15}$ reported the synthesis of high entropy transition metal oxide systems by co-precipitation as well as mechanical grinding. However, they obtained a single-phase solid solution only after calcination at $900{ }^{\circ} \mathrm{C}$. Gild et al. ${ }^{17}$ synthesized fluorite oxides by ball milling followed by spark plasma sintering at $1500{ }^{\circ} \mathrm{C}$ to obtain a single phase material. Similarly, Djenadic et al. ${ }^{11}$ synthesized single-phase rare-earth multicomponent oxides using nebulized spray pyrolysis at $1150{ }^{\circ} \mathrm{C}$. If singlephase, high-entropy oxides can be obtained at room temperature without further heat treatment, then their production cost and time can be reduced significantly. Moreover, the reported

Department of Materials Science and Metallurgical Engineering, Indian Institute of Technology Hyderabad, Kandi, Sangareddy-502285, India. E-mail: atuldeshpande@ iith.ac.in; Tel: +91-4023017044

$\dagger$ Electronic supplementary information (ESI) available. See DOI: 10.1039/c9ra04636d synthesis methods for high-entropy oxides typically yield submicron-sized particles with non-uniform size distribution. ${ }^{11}$ For various applications, controlled particle size and powders in non-agglomerated are essential. Bottom-up approaches to obtain nanostructured materials such as templating techniques or self-assembly processes also require nanoparticles in a stable sol form. ${ }^{21}$

For applications, such as automotive exhaust catalysis (TWC) and electrode materials for solid oxide fuel cells (SOFC), high surface area and microstructural stability at elevated temperatures are essential attributes. ${ }^{21-23}$ However, the conventional ceramic materials used for TWC and SOFC applications undergo rapid particle size growth at high temperatures, decreasing effective surface area more quickly. Thus, limiting their functional life for high temperature applications. ${ }^{24}$ The approaches such as doping with one or more elements have been used to restrict the crystallite growth to make them suitable for high temperature applications have met with limited success. ${ }^{25}$ In this regard, high entropy oxides can be considered as a better alternative to conventional materials, since one of the characteristic features of high entropy materials is that they show restricted grain growth due to sluggish diffusion. Consequently, the restricted grain growth can prevent loss of surface area and provide extended functional life time. However, as mentioned before, the reported methods for the synthesis of high entropy oxide yield submicron-sized particles which makes them unsuitable to obtain high surface area, porous materials.

Thus, in order to fulfill the requirements for TWC and SOFC applications, we demonstrate for the first time, a simple and scalable method to synthesize single phase, high entropy fluorite oxide nanoparticles sols $\left(\mathrm{Gd}_{0.2} \mathrm{La}_{0.2} \mathrm{Y}_{0.2} \mathrm{Hf}_{0.2} \mathrm{Zr}_{0.2} \mathrm{O}_{2}\right.$ and $\mathrm{Gd}_{0.2} \mathrm{La}_{0.2} \mathrm{Ce}_{0.2} \mathrm{Hf}_{0.2} \mathrm{Zr}_{0.2} \mathrm{O}_{2}$ ). The amounts of constituent elements in both the compositions are equimolar because, for 
a multicomponent system, maximum configurational entropy is attained when the system possess equimolar composition as per the following equation

$$
S_{\text {config }}=-R\left(\sum_{i=1}^{N} x_{i} \ln x_{i}\right)
$$

where $x_{i}$ denotes the mole fractions of ions and $R$ is the gas constant (8.314 J per K per mole). ${ }^{26}$ The individual metal oxides in both these compositions are known for their application in catalysis, solid oxide fuel cells and thermal barrier coatings. ${ }^{22,27-30}$ The synthesis was carried at low temperature by coprecipitation followed by re-dispersion in acidic medium by ultrasonication. The obtained nanoparticles were fully crystalline, single phase fluorite oxides with particle size in the range of 2-3 nm. The structural and morphological studies of both $\mathrm{Gd}_{0.2} \mathrm{La}_{0.2} \mathrm{Y}_{0.2} \mathrm{Hf}_{0.2} \mathrm{Zr}_{0.2} \mathrm{O}_{2}$ and $\mathrm{Gd}_{0.2} \mathrm{La}_{0.2} \mathrm{Ce}_{0.2} \mathrm{Hf}_{0.2} \mathrm{Zr}_{0.2} \mathrm{O}_{2}$ systems were carried out which will be discussed below.

\section{Experimental}

\subsection{Synthesis}

The $\mathrm{Gd}_{0.2} \mathrm{La}_{0.2} \mathrm{Y}_{0.2} \mathrm{Hf}_{0.2} \mathrm{Zr}_{0.2} \mathrm{O}_{2}$ and $\mathrm{Gd}_{0.2} \mathrm{La}_{0.2} \mathrm{Ce}_{0.2} \mathrm{Hf}_{0.2} \mathrm{Zr}_{0.2} \mathrm{O}_{2}$ sols were synthesized based on process reported earlier by Deshpande et $a{ }^{31}{ }^{31}$ For a typical synthesis, 0.001 moles each of cerium ammonium nitrate $\left(\mathrm{Ce}\left(\mathrm{NH}_{4}\right)_{2}\left(\mathrm{NO}_{3}\right)_{6}\right.$, Sigma-Aldrich, 98.5\%), yttrium nitrate hexahydrate $\left(\mathrm{Y}\left(\mathrm{NO}_{3}\right)_{3} \cdot 6 \mathrm{H}_{2} \mathrm{O}\right.$, SigmaAldrich, 99.8\%), zirconyl chloride octahydrate $\left(\mathrm{ZrOCl}_{2} \cdot 8 \mathrm{H}_{2} \mathrm{O}\right.$, Sigma-Aldrich, 98\%), lanthanum nitrate hexahydrate $\left(\mathrm{La}\left(\mathrm{NO}_{3}\right)_{3} \cdot 6 \mathrm{H}_{2} \mathrm{O}\right.$, Alfa Aesar, 99.9\%), gadolinium nitrate hydrate $\left(\mathrm{Gd}\left(\mathrm{NO}_{3}\right)_{3} \cdot \mathrm{H}_{2} \mathrm{O}\right.$, Alfa Aesar, 99.9\%), and hafnium chloride $\left(\mathrm{Cl}_{4} \mathrm{Hf}\right.$, Alfa Aesar, 98\%) were dissolved together in $30 \mathrm{ml}$ deionized (DI) water and required amount of ammonia solution $\left(\mathrm{NH}_{4} \mathrm{OH}\right.$, Merck, 25\%) was added to this mixed solution to increase the $\mathrm{pH}$ above 12 . The obtained precipitate was quickly centrifuged and washed with DI water multiple times until $\mathrm{pH}$ of 7 was achieved. If the precipitates are allowed to age, the process of peptization does not yield transparent sols. Therefore, immediately after washing step (i.e. after reaching a $\mathrm{pH}$ of 7), $5 \mathrm{ml}$ of DI water and calculated amount of nitric acid $\left(\mathrm{HNO}_{3}\right.$, Merck, 69\%) (1: 1.5 metal ion to $\mathrm{HNO}_{3}$ ratio) were added to the washed precipitate and shaken vigorously. The resultant suspension was sonicated using a probe sonicator equipped with in-built temperature sensor (Sonics Vibra-Cell VCX 750, 750 watts, $20 \mathrm{kHz}$ ). The sonication was carried out with an amplitude of $60 \%$ of power. During sonication, a temperature cut off of $80{ }^{\circ} \mathrm{C}$ was set to prevent solvent evaporation. Thus sonication stopped automatically when the temperature reached $80^{\circ} \mathrm{C}$ and started again when temperature went below $80^{\circ} \mathrm{C}$. This intermittent sonication was continued for about 1.5 hours until the formation of transparent sol. For XRD studies, the obtained transparent sols were dried in an oven at $110{ }^{\circ} \mathrm{C}$ for 24 hours. After drying, samples were washed with ethanol and dried at $100{ }^{\circ} \mathrm{C}$ for 12 hours. Additionally, the dried powders were calcined in a muffle furnace (static air) at $500{ }^{\circ} \mathrm{C}$ for 4 hours. The samples were labeled as GLCHZ-RT and GLYHZ-RT for as-synthesized, oven dried $\mathrm{Gd}_{0.2} \mathrm{La}_{0.2} \mathrm{Ce}_{0.2} \mathrm{Hf}_{0.2} \mathrm{Zr}_{0.2} \mathrm{O}_{2}$ and
$\mathrm{Gd}_{0.2} \mathrm{La}_{0.2} \mathrm{Y}_{0.2} \mathrm{Hf}_{0.2} \mathrm{Zr}_{0.2} \mathrm{O}_{2}$ powdered samples respectively. And GLCHZ-500 and GLYHZ-500 for powdered samples calcined at $500{ }^{\circ} \mathrm{C}$ for 4 hours respectively.

\subsection{Characterization}

For as-synthesized powders, the crystallinity of the samples was studied using XRD (Rigaku Ultima IV, Rigaku) with $\mathrm{Cu}-\mathrm{K}_{\alpha}$ radiation $(\lambda=1.54 \AA)$ with a scan speed of $0.16^{\circ}$ per min and $0.08^{\circ}$ per min respectively for GLCHZ-RT and GLYHZ-RT in the range of $20-80^{\circ}$. The crystallinity of calcined samples was studied using XRD (Discover D8, Bruker) with $\mathrm{Cu}-\mathrm{K}_{\alpha}$ radiation $(\lambda$ $=1.54 \AA$ ) with a step size of $0.01^{\circ}$ and an exposure time of 11 seconds per step from $20-80^{\circ}$. Rietveld refinement was done using Fullprof program for both as-synthesized and calcined samples. ${ }^{32}$ Refinement parameters include; sample displacement, background correction, scale factor, half-width parameters, lattice parameters, atomic fractional position coordinates, and thermal parameters. Williamson-Hall $(\mathrm{W}-\mathrm{H})$ analysis was done to assess the contribution of crystallite size and the microstrain in XRD peak broadening. ${ }^{33}$ HRTEM images were captured using JEOL (JEOL JEM-2100, JEOL) microscope operated at a potential of $200 \mathrm{kV}$. For HRTEM imaging of assynthesized samples, the sols were diluted with DI water $(1 \mathrm{ml}$ sol : $9 \mathrm{ml}$ DI water), drop-casted over TEM grid and dried at room temperature. For HRTEM imaging of calcined samples, powdered samples were ultrasonically dispersed in DI water, drop-casted on TEM grid and dried at room temperature. Similarly, elemental quantification was done using inductively coupled plasma-optical emission spectrometer (ICP-OES, ICPOES 720, Agilent) as well as by energy-dispersive X-ray spectroscopy (EDS) equipped with field emission scanning electron microscopy (FESEM) (JEOL JSM 7800F, JEOL). Fouriertransform infrared spectroscopy (FTIR) studies were performed on nano powders using Bruker Tensor 37 (Bruker). Sample preparation involved preparation of pellet by mixing nanopowder and $\operatorname{KBr}(1: 200$ weight ratio). Data was collected in transmittance mode from $400-4000 \mathrm{~cm}^{-1}$.

\section{Results and discussion}

In the present work, we would like to highlight a low temperature synthesis protocol $\left(\leq 80{ }^{\circ} \mathrm{C}\right)$ where we were able to design a simplistic approach to obtain a single phase high entropy oxide composition. For both the compositions $\left(\mathrm{Gd}_{0.2} \mathrm{La}_{0.2} \mathrm{Y}_{0.2^{-}}\right.$ $\mathrm{Hf}_{0.2} \mathrm{Zr}_{0.2} \mathrm{O}_{2}$ and $\mathrm{Gd}_{0.2} \mathrm{La}_{0.2} \mathrm{Ce}_{0.2} \mathrm{Hf}_{0.2} \mathrm{Zr}_{0.2} \mathrm{O}_{2}$ ), the solubility of all individual metal hydroxides is quite negligible. Therefore, we used ammonium hydroxide as a precipitating agent to effect coprecipitation of mixed metal hydroxides. The peptization was brought about by the addition of nitric acid. The addition of nitric acid coupled with sonication not only results in peptization but also leads to crystallization of mixed metal oxides via dissolution and recrystallization process. ${ }^{31}$

Fig. 1 shows the XRD patterns of as-synthesized powders of $\mathrm{Gd}_{0.2} \mathrm{La}_{0.2} \mathrm{Ce}_{0.2} \mathrm{Hf}_{0.2} \mathrm{Zr}_{0.2} \mathrm{O}_{2}$ and $\mathrm{Gd}_{0.2} \mathrm{La}_{0.2} \mathrm{Y}_{0.2} \mathrm{Hf}_{0.2} \mathrm{Zr}_{0.2} \mathrm{O}_{2}$ nanoparticles. The patterns are quite similar to that of oxides with a cubic fluorite structure. The obtained pattern was compared 

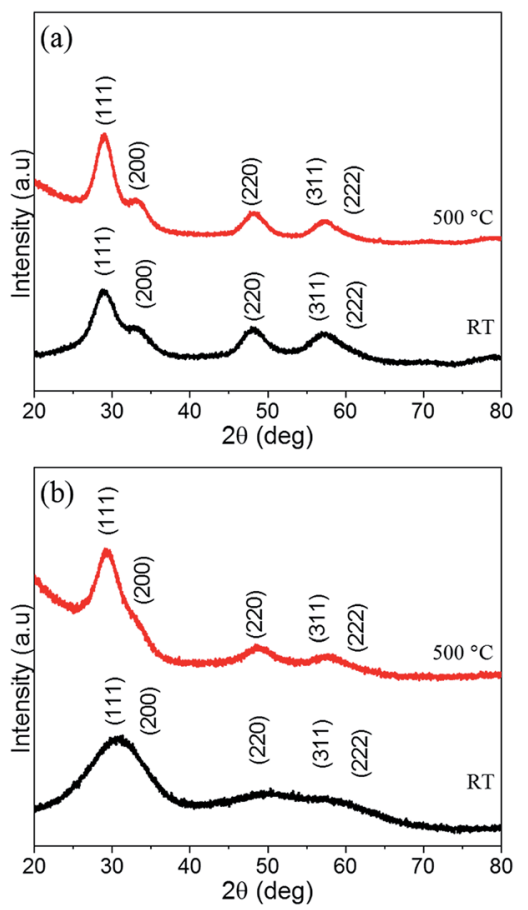

Fig. $1 \mathrm{X}$-ray diffraction pattern of as-synthesized and calcined (a) $\mathrm{Gd}_{0.2} \mathrm{La}_{0.2} \mathrm{Ce}_{0.2} \mathrm{Hf}_{0.2} \mathrm{Zr}_{0.2} \mathrm{O}_{2}$ and (b) $\mathrm{Gd}_{0.2} \mathrm{La}_{0.2} \mathrm{Y}_{0.2} \mathrm{Hf}_{0.2} \mathrm{Zr}_{0.2} \mathrm{O}_{2}$ nanoparticles.

with standard $\mathrm{CeO}_{2}$ because the crystal structure of $\mathrm{CeO}_{2}$ is cubic fluorite throughout the temperature range studied here. However, the peak positions are shifted at higher angles indicating a unique set of lattice parameters smaller than that of standard $\mathrm{CeO}_{2}$. The decrease in lattice parameter in our system may be attributed to the variation in ionic radii, valence, electronegativity, and metal oxygen bond strength of the five constituent cations, which in turn may be responsible for large lattice strain and smaller lattice parameter compared to standard $\mathrm{CeO}_{2}$. Existence of broad reflections indicate small crystallite size as well as micro strain. Absence of any other peaks indicate that single phase solid solution is obtained at mild temperature. Additionally, Rietveld refinement was carried out in order to confirm single phase nature of as-synthesized samples. Fig. S1 $\uparrow$ shows a good fit with the experimental data and the corresponding lattice parameter obtained is $5.343 \AA$ and $5.340 \AA$ for GLYHZ-RT and GLCHZ-RT samples, respectively.

In order to explore the local structure, HRTEM was performed on as-synthesized powders. Fig. 2 shows the HRTEM images of as-synthesized nanoparticles of GLCHZ-RT and GLYHZ-RT. The size of individual particles was measured manually by random selection. Based on 50 measurements, the particle size distribution was found to be narrow and the average particle size for both GLCHZ-RT and GLYHZ-RT samples were in the range of $2.5 \mathrm{~nm}$ (Fig. 2(d) and (h)) matching well with that of values obtained through $\mathrm{W}-\mathrm{H}$ plot (Fig. S5 and Table S4†). The individual particles show well-defined lattice fringes, indicating that the nanoparticles are very well crystallized. As seen from Fig. $2(\mathrm{c})$ and (g), the SAED patterns for both samples show diffused ring pattern owing to random orientation of nanosized particles. Based on the interplanar spacing ( $d$ spacing) calculated from SAED pattern (Table S1 $\dagger$ ), the individual rings can be indexed to (111), (200), (220), and (311) planes of cubic fluorite structure similar to cubic ceria or cubic yttria stabilized zirconia. The difference in $d$ spacing for GLCHZ-RT and GLYHZ-RT and that observed for standard cubic fluorite oxides is due to the difference in ionic radii of individual metal ions as well as their oxidation states. Moreover, no other additional spots or rings can be observed in SAED pattern indicating single phase nature of nanoparticles without any microphase separation. Fig. 2(b) and (f) show individual nanoparticles of GLCHZ-RT and GLYHZ-RT respectively. The $d$ values calculated from the spacing between well-defined lattice fringes of these particles was $0.32 \mathrm{~nm}$ and $0.30 \mathrm{~nm}$ for GLCHZ-RT and GLYHZ-RT respectively. These values match with $d$ spacing corresponding to (111) planes calculated from the corresponding SAED pattern. From the HRTEM images, we can conclude that well crystallized, single phase oxides with controlled size can easily be synthesized at temperature below $80{ }^{\circ} \mathrm{C}$ through simple co-precipitation-peptization method. In order to check the chemical composition of as-synthesized powders, SEM-EDS and ICP-OES spectroscopy analysis were carried out. Table S2 $\uparrow$ shows the chemical composition of as-synthesized powders using SEM-EDS and ICP-OES. The values showed a nearly equimolar concentration of all cations. A small deviation from equimolar stoichiometry values may be due to difference in chemical purity of as-received metal salt precursors used in the synthesis. Based on the ICP-OES analysis, the stoichiometry of GLYHZ-RT and GLCHZ-RT will be $\mathrm{Gd}_{0.18} \mathrm{La}_{0.22} \mathrm{Y}_{0.24} \mathrm{Hf}_{0.18} \mathrm{Zr}_{0.18^{-}}$ $\mathrm{O}_{1.68}$ and $\mathrm{Gd}_{0.17} \mathrm{La}_{0.22} \mathrm{Ce}_{0.24} \mathrm{Hf}_{0.19} \mathrm{Zr}_{0.18} \mathrm{O}_{1.81}$ respectively assuming ceria exists in $4+$ oxidation state.

It is known that nanoparticles of oxide systems consisting of two or more components prepared by co-precipitation method often show stabilization of metastable phases due to small particle size and micro strain. ${ }^{21}$ However, upon heat treatment, these systems show phase transformation or phase separation. Thus to assess the phase stability of our oxides, the assynthesized powders were calcined at $500{ }^{\circ} \mathrm{C}$ for 4 hours. Fig. 1(a) and (b) shows the XRD patterns of GLCHZ-500 and GLYHZ-500 samples with the diffraction pattern indexed to a cubic fluorite structure. Absence of any other peaks indicate that these samples remain single phase even after calcination. In addition to that, the peaks were still sufficiently broad which may be due to microstrain present in the system as a result of different sized cation occupying different lattice sites. Similarly, FTIR spectra (Fig. S3 and Table S3†) show the presence of nitrates in the as-synthesized powders as nitric acid was used as peptizating agent during the synthesis process. These vibrations disappear for calcined samples indicating decomposition of nitrates during heat treatment. From the FTIR spectra, we confirm that no organics were present in the as-synthesized GLCHZ and GLHZ powders.

Rietveld refinements of GLCHZ and GLYHZ samples calcined at $500{ }^{\circ} \mathrm{C}$ using a fluorite structure model clearly show excellent fit with the experimental data (Fig. S2 and Table S4†). Thus, we confirm that the high entropy system remains single 

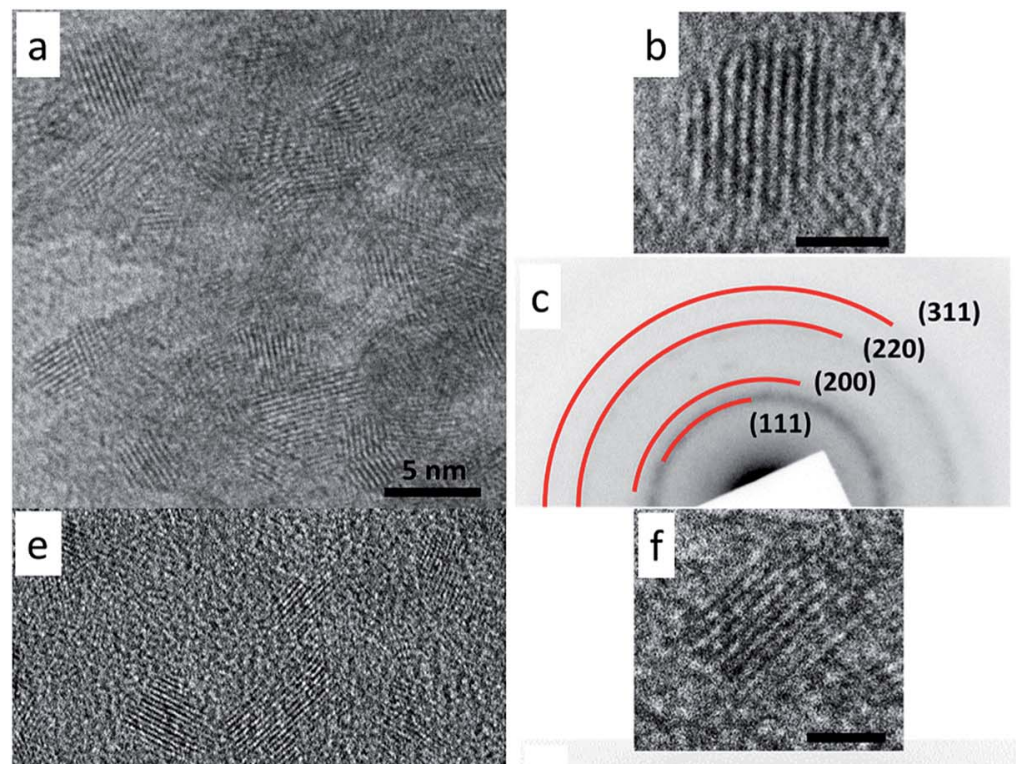

g
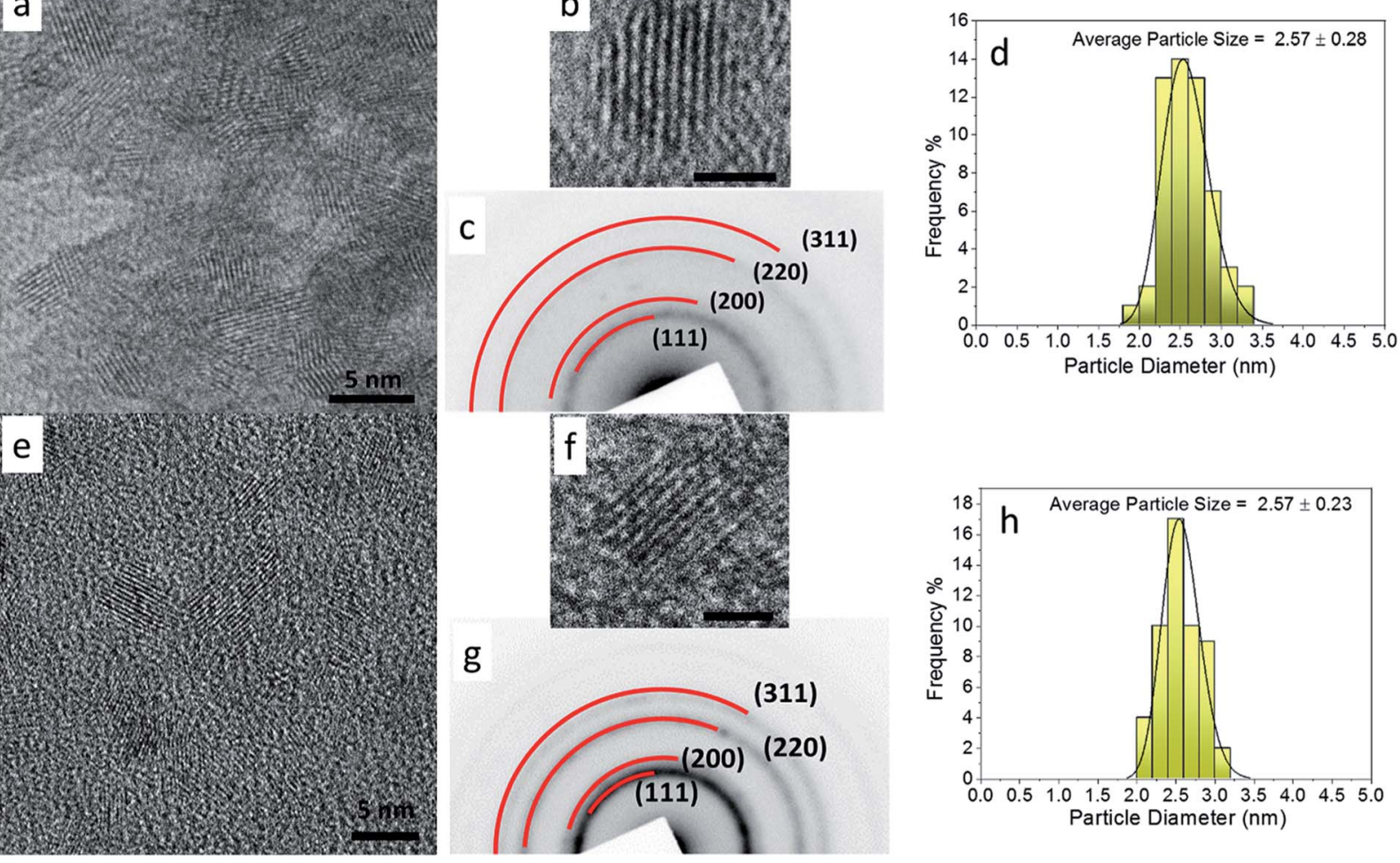

Fig. 2 (a) and (e) HRTEM image, (b) and (f) isolated particle, (c) and (g) SAED pattern, (d) and (h) particle size distribution of GLCHZ-RT and GLYHZ-RT respectively (scale bar in image (b) and (f) corresponds to $2 \mathrm{~nm}$ ).

phase after heat treatment without any structural distortions or phase separation. Table $\mathrm{S} 4 \uparrow$ shows that the calculated lattice parameter for GLCHZ-500 and GLYHZ-500 are $5.346 \AA$ and 5.338 $\AA$ respectively. The calculated crystallite sizes for GLCHZ-500 and GLYHZ-500 were $3.1 \mathrm{~nm}$ and $5.5 \mathrm{~nm}$ with corresponding microstrain of $0.2 \%$ and $2.98 \%$ respectively (calculated from $\mathrm{W}-\mathrm{H}$ plots as shown in Fig. S6†). Therefore, larger peak width observed in XRD pattern of GLYHZ-500 as compared to GLCHZ500 can be attributed to the difference in microstrain observed for both the samples. The large amount of microstrain may be responsible for restricted crystallite growth upon heat treatment for both the samples.

Fig. 3 shows the HRTEM images of GLCHZ-500 and GLYHZ500 powders. The measured particle size for both GLCHZ-500 and GLYHZ-500 samples were in the range of $4-5 \mathrm{~nm}$. The SAED patterns showed a diffused ring pattern similar to that of as synthesized nanoparticles. Absence of additional spots or rings confirms that nanoparticles of both the samples retain single phase cubic fluorite structure upon calcination. Thus, from the comparison of XRD and SAED data, it is clear that heat treatment at $500{ }^{\circ} \mathrm{C}$ does not lead to destabilization of single phase cubic fluorite structure. The $d$-spacing calculated from SAED patterns are $0.32 \mathrm{~nm}$ and $0.31 \mathrm{~nm}$ respectively for GLCHZ500 and GLYHZ-500. These values match with $d$ spacing corresponding to (111) planes calculated from XRD pattern. Based on the results discussed, the obtained nanoparticles upon heat treatment tend to grow in a sluggish manner which is a characteristics of high entropy system. To further assess the phase stability of the multicomponent oxides, we calcined GLCHZ sample at $750{ }^{\circ} \mathrm{C}$ for 4 hours and $1000{ }^{\circ} \mathrm{C}$ for 4 hours. The XRD patterns (Fig. S4 $\dagger$ ) clearly show retention of single phase cubic fluorite structure. The broad peaks also indicate that the crystallite size increase upon higher temperature calcination was still not very significant when compared with crystallite sizes observed for as-synthesized and $500^{\circ} \mathrm{C}$ calcined samples (Table $\mathrm{S} 4 \dagger)$. The Rietveld refinement analysis of these XRD patterns

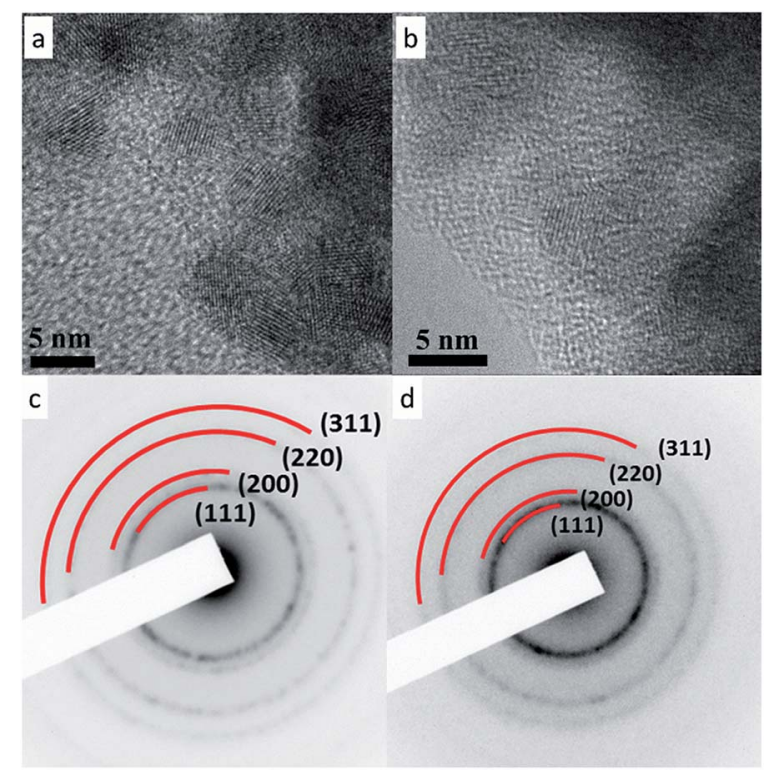

Fig. 3 HRTEM images of (a) GLCHZ and (b) GLYHZ calcined at $500^{\circ} \mathrm{C}$ for $4 \mathrm{~h}$ and its corresponding SAED patterns ( $c$ and $\mathrm{d}$ ). 
also show excellent fit with cubic fluorite geometry indicating phase pure nature of GLCHZ. Further studies to assess phase and microstructural stability upon prolonged heat treatment at higher temperatures $\left(\geq 1000{ }^{\circ} \mathrm{C}\right)$ is currently underway and will be reported separately.

\section{Conclusions}

In summary, we have successfully demonstrated the synthesis of single phase multicomponent fluorite oxide nanoparticle sols by co-precipitation-peptization method under mild conditions $\left(\leq 80{ }^{\circ} \mathrm{C}\right)$. The HRTEM and XRD results confirm that both GLCHZ and GLYHZ compositions crystallize in single phase cubic fluorite structure having a particle size of $2.5 \mathrm{~nm}$. Calcination at $500{ }^{\circ} \mathrm{C}$ of both GLCHZ and GLYHZ still yielded single phase materials with the retention of cubic fluorite structure. Rietveld refinement of XRD data of both as-synthesized and calcined samples show excellent fit with experimental data confirming that both GLCHZ and GLYHZ compositions show formation of single phase high entropy oxides with cubic fluorite structure. The GLCHZ sample heat treated at $750{ }^{\circ} \mathrm{C}$ and $1000{ }^{\circ} \mathrm{C}$ also showed excellent phase stability and restricted grain growth. Overall, the method reported here is quite advantageous for the synthesis of high entropy oxides when compared to other reported synthesis methods such as ball milling, spray pyrolysis in terms of ease of preparation, cost effectiveness and scalability. In addition, well dispersed nanoparticles in solvent medium make them useful for bottom-up approaches such as self-assembly or templating techniques to obtain nanostructured high entropy oxide materials. The small particle size, restricted crystallite growth and excellent phase stability observed for our system will be highly advantageous for applications such as solid oxide fuel cells, catalysis and thermal barrier coatings.

\section{Conflicts of interest}

There are no conflicts to declare.

\section{Acknowledgements}

We are grateful to Indian Institute of Technology Hyderabad for providing financial assistance and necessary characterization facilities. We would like to thank Dr Joyita Bhattacharya for fruitful discussions. Also we would like to acknowledge DSTFIST program (Grant no. SR/FST/ETI-421/2016) for providing EDS facility. We would like to thank Ms Pujitha for carrying out FTIR measurements.

\section{References}

1 C.-W. Tsai, S.-W. Lai, K.-H. Cheng, M.-H. Tsai, A. Davison, C.-H. Tsau and J.-W. Yeh, Thin Solid Films, 2012, 520, 2613-2618.

2 A. D. Pogrebnjak, I. V. Yakushchenko, G. Abadias, P. Chartier, O. V. Bondar, V. M. Beresnev, Y. Takeda,
O. V. Sobol', K. Oyoshi, A. A. Andreyev and B. A. Mukushev, J. Superhard Mater., 2013, 35, 356-368.

3 A. D. Pogrebnjak, A. A. Bagdasaryan, I. V. Yakushchenko and V. M. Beresnev, Russ. Chem. Rev., 2014, 83, 1027-1061.

4 X. Yan, L. Constantin, Y. Lu, J.-F. Silvain, M. Nastasi and B. Cui, J. Am. Ceram. Soc., 2018, 101, 4486-4491.

5 E. Castle, T. Csanádi, S. Grasso, J. Dusza and M. Reece, Sci. Rep., 2018, 8, 8609.

6 A. Sarkar, L. Velasco, D. Wang, Q. Wang, G. Talasila, L. de Biasi, C. Kübel, T. Brezesinski, S. S. Bhattacharya, H. Hahn and B. Breitung, Nat. Commun., 2018, 9, 3400.

7 P. Sarker, T. Harrington, C. Toher, C. Oses, M. Samiee, J.-P. Maria, D. W. Brenner, K. S. Vecchio and S. Curtarolo, Nat. Commun., 2018, 9, 4980.

8 C. M. Rost, E. Sachet, T. Borman, A. Moballegh, E. C. Dickey, D. Hou, J. L. Jones, S. Curtarolo and J.-P. Maria, Nat. Commun., 2015, 6, 8485.

9 D. Bérardan, S. Franger, D. Dragoe, A. K. Meena and N. Dragoe, Phys. Status Solidi Rapid Res. Lett., 2016, 10, 328-333.

10 D. Bérardan, S. Franger, A. Meena and N. Dragoe, J Mater Chem A, 2016, 4, 9536-9541.

11 R. Djenadic, A. Sarkar, O. Clemens, C. Loho, M. Botros, V. S. K. Chakravadhanula, C. Kübel, S. S. Bhattacharya, A. S. Gandhi and H. Hahn, Mater. Res. Lett., 2017, 5, 102-109.

12 A. Sarkar, R. Djenadic, N. J. Usharani, K. P. Sanghvi, V. S. K. Chakravadhanula, A. S. Gandhi, H. Hahn and S. S. Bhattacharya, J. Eur. Ceram. Soc., 2017, 37, 747-754.

13 A. Sarkar, C. Loho, L. Velasco, T. Thomas, S. S. Bhattacharya, H. Hahn and R. Djenadic, Dalton Trans., 2017, 46, 1216712176.

14 A. Sarkar, R. Djenadic, D. Wang, C. Hein, R. Kautenburger, O. Clemens and H. Hahn, J. Eur. Ceram. Soc., 2018, 38, 2318-2327.

15 H. Chen, J. Fu, P. Zhang, H. Peng, C. W. Abney, K. Jie, X. Liu, M. Chi and S. Dai, J Mater Chem A, 2018, 6, 11129-11133.

16 M. Biesuz, L. Spiridigliozzi, G. Dell'Agli, M. Bortolotti and V. M. Sglavo, J. Mater. Sci., 2018, 53, 8074-8085.

17 J. Gild, M. Samiee, J. L. Braun, T. Harrington, H. Vega, P. E. Hopkins, K. Vecchio and J. Luo, J. Eur. Ceram. Soc., 2018, 38, 3578-3584.

18 D. Berardan, A. K. Meena, S. Franger, C. Herrero and N. Dragoe, J. Alloys Compd., 2017, 704, 693-700.

19 S. Jiang, T. Hu, J. Gild, N. Zhou, J. Nie, M. Qin, T. Harrington, K. Vecchio and J. Luo, Scr. Mater., 2018, 142, 116-120.

20 J. Dą̧browa, M. Stygar, A. Mikuła, A. Knapik, K. Mroczka, W. Tejchman, M. Danielewski and M. Martin, Mater. Lett., 2018, 216, 32-36.

21 A. S. Deshpande and M. Niederberger, Microporous Mesoporous Mater., 2007, 101, 413-418.

22 A. Mastalir, B. Frank, A. Szizybalski, H. Soerijanto, A. Deshpande, M. Niederberger, R. Schomäcker, R. Schlögl and T. Ressler, J. Catal., 2005, 230, 464-475.

23 A. S. Deshpande, N. Pinna, B. Smarsly, M. Antonietti and M. Niederberger, Small, 2005, 1, 313-316.

24 T. Montini, M. Melchionna, M. Monai and P. Fornasiero, Chem. Rev., 2016, 116, 5987-6041. 
25 Y. Zhou, J. Deng, L. Xiong, J. Wang, S. Yuan, H. Zhang and Y. Chen, Mater. Des., 2017, 130, 149-156.

26 J. W. Yeh, S. K. Chen, S. J. Lin, J. Y. Gan, T. S. Chin, T. T. Shun, C. H. Tsau and S. Y. Chang, Adv. Eng. Mater., 2004, 6, 299-303.

27 J. Kašpar, P. Fornasiero and M. Graziani, Catal. Today, 1999, 50, 285-298.

28 L. Guo, M. Li, Y. Zhang and F. Ye, J. Mater. Sci. Technol., 2016, 32, 28-33.
29 E. V. Tsipis and V. V. Kharton, J. Solid State Electrochem., 2008, 12, 1367-1391.

30 S. P. Jiang and S. H. Chan, J. Mater. Sci., 2004, 39, 4405-4439. 31 A. S. Deshpande, N. Pinna, P. Beato, M. Antonietti and M. Niederberger, Chem. Mater., 2004, 16, 2599-2604.

$32 \mathrm{~J}$. Rodríguez-Carvajal, Newsletter of the Commission for Powder Diffraction of the IUCr, 2001, vol. 26, pp. 12-19.

33 G. K. Williamson, W. H. Hall, Acta Metall., 1953, vol.1, 22-31. 